\title{
Adrenergic Control of Motor Activity: Effects of PNMT Inhibition Upon Open Field Behavior in the Rat
}

\author{
R. J. KATZ, BARBARA B. TURNER, KEVIN ROTH AND BERNARD J. CARROLL \\ Mental Health Research Institute, Department of Psychiatry, University of Michigan Medical Center, Ann \\ Arbor, MI 48109
}

(Received 11 May 1978)

\begin{abstract}
KATZ. R. J., B. B. TURNER, K. ROTH AND B. J. CARROLL. Adrenergic control of motor actirity: Effects of PNMT inhihition upon open field behavior in the rat. PHARMAC. BIOCHEM. BEHAV. 9(4) 417-420, 1978.-Two inhibitors of hrain PNMT were given to rats in doses which caused equivalent reductions in enzyme activity. Each drug produced similar and dose-related decreases in ambulation, rearing and defecation during open field behavioral testing. Central adrenergic (epinephrine containing) systems may be necessary for normal open field behavior. This may reflect an interaction with other monoamines, particularly dopamine.
\end{abstract}

Catecholamines Dopamine DCMB Defecation Epinephrine Motor activity Open field
PNMT Psychomotor Rearing SKF64139

THE CATECHOLAMINES (CA), norepinephrine (NE) and dopamine (DA) are known to play critical roles in motor integration and psychomotor activation. For example, 1-DOPA (1-dihydroxyphenylalanine), the precursor to CA, produces a syndrome of motor activation after systemic injection [32] and central stimulation of $N E$ and $D A$ postsynaptic receptors increases motor activity $13,13,15$, 16. 21, 23. 29. 34, 351. CA depleting agents have an opposite (i.e., motor inhibitory) effect $[1,31,34,35]$.

Several reports have suggested the existence of a third functional CA neurotransmitter in the CNS. The biosynthetic enzyme for epinephrine ( $E$ ) has been localized in hindbrain cell hodies $[10,19,27]$ and both cell bodies and terminal varicosities have been visualized through immunohistofluorescent microscopy [10.14]. Also, epinephrine itself has been demonstrated centrally [2]. Relatively few studies have specifically addressed the role of $\mathrm{E}$ in motor activity.

Several studies dating from the early part of the century reported sedation. depression, and stupor after central $E$ administration (summarized in [22]). However, these studies invariably employed physiologically supranormal amounts of transmitter; more recent studies using lower doses and improved infusion techniques suggest $E$ neurons may be motor excitatory $[5,12,23]$, note however $[11]$. If $E$ neurons are necessary for motor atctivity, it follows that inhibition of E synthesis should causc motor depression. In a preliminary communication we reported that inhibitors of PNMT, the synthesizing enzyme for E. produced an acute lowering of spontaneous motor activity [17]. The present experiments extend these observations by testing two inhibitors of hrain PNMT for their effects on open field behavior.

\begin{abstract}
METHOI)
Animals

Ninety adult male Sprague-Dawley rats $(200-275 \mathrm{~g})$ (Charles River, Portage, MI) randomly chosen from our colony were used for behavioral testing. An additional 23 rats were used for biochemical determinations. All animals were maintained upon ad lib food (Teklad 4.0\% fat diet S-0836) and water, and automatically programmed $12 \mathrm{hr}$ light/12 hr dark cycles.
\end{abstract}

\section{Apparatlus}

Animals were tested in a $1.22 \mathrm{~m}^{2}$ white Plexiglas field containing sixteen $30.5 \mathrm{~cm}^{2}$ squares for the assessment of locomotion. The open field was washed between tests. A hackground masking noise of approximately $20 \mathrm{~dB}$ was provided by an air circulation system. Two $75 \mathrm{~W}$ fluorescent lights located $3 \mathrm{~m}$ from the apparatus provided a difuse low level of illumination.

\section{Druge:}

Lilly DCMB [7] (2,3-dichloro- $\alpha$-methylbenzylamine), 0 , 12.5 and $25.0 \mathrm{mg} / \mathrm{kg}$ and SKF 64139 [18] (7,8-dichloro, 1, 2 , 3. 4-tetrahydroisoquinoline $\mathrm{HCl}) 0,10$ and $40 \mathrm{mg} / \mathrm{kg}$ were injected intraperitoneally $(1 \mathrm{ml} / \mathrm{kg})$ in a $0.9 \%$ sodium chloride vehicle solution $1 \mathrm{hr}$ prior to testing or biochemical assay. DCMB is known to lower central epinephrine without affecting other catecholamines [8]. SKF64139 also has this effect and in other tests has been shown to cause slight increases in serotonin only at doses considerably in excess of those em- 
ployed in the present design [18]. Other studies have shown the latter to be free of effects upon monoamine oxidase or catechol-o-methyltransferase at the doses presently employed [18]. It should be noted that based upon studies in our laboratory of the dose response relationship of these compounds (Turner e: al.. in preparation), the low and high doses of each drug were chosen to produce equivalent enzyme inhibition across compounds.

\section{Behavioral Procedure}

One hour after initial injection of drug or vehicle animals were individually placed in the open field. Except for the actual transportation of animals from their cages to the open field, this was the only handling they experienced during the experiment. Grid crossings, rearings, and defecation were recorded for 4 consecutive 3 min periods. All animals from all conditions were tested on more than 1 occasion and received each treatment. However, a minimum of $48 \mathrm{hr}$ intervened between any repeated tests. Repeated testing produced (equivalent) lowering of initial activity across conditions.

\section{Biochemical Procedure}

At $1 \mathrm{hr}$ animals matched for drug treatment, weight, and supplier with behaviorally tested animals were sacrificed by decapitation. Brains were removed and dissected upon a chilled glass plate. A $5 \times 8 \mathrm{~mm}$ rectangular punch was used to standardize dissection of the pons-medulla which includes the $C_{1}$ and $C_{2}$ adrenergic nuclei as defined by Hokfelt $e^{\prime} l$ al. [14]. Brain tissue was immediately frozen in liquid nitrogen and stored at $-30^{\circ} \mathrm{C}$ prior to assay. PNMT was assayed according to the procedure of Pendleton $[24]$ with several modifications including the use of "H-methyl-Sadenosylmethionine (New England Nuclear Corp.) as the methyl donor together with unlabelled carrier and the elimination of acid extraction of the labelled product. Triplicate determinations were performed on all samples. Proteins were measured by the method of Lowry [20]. Additional details of the assay procedure have been published elsewhere $|33|$.

\section{Statistic:s}

All comparisons were by Analysis of Variance. All results are presented as mean and standard error. Analysis of variance was by a two-factor mixed design ANOVA with repeated measures on one factor $[6 \mid$. Factors analyzed were dosage and time, and the BMOD2Y program for analysis of variance of the health sciences computing facility of the University of California was used for the actual analyses. Individual analyses were performed for each behavior. Also. randomized design ANOVA was used for defecation scores.

\section{RESULTS}

Biochemical results. The PNMT inhibitors each reduced central enzyme activity in a dose related manner. DCMB $(12.5 \mathrm{mg} / \mathrm{kg})$ and SKF $64139(10 \mathrm{mg} / \mathrm{kg})$ produced $48 \%$ and $47 \%$ inhibition in comparison to control animals and DCMB $(25.0 \mathrm{mg} / \mathrm{kg})$ and $64139(40 \mathrm{mg} / \mathrm{kg})$ produced 60 and $62 \%$ inhibition in comparison to control animals. Actual brainstem activity for control animals was $37.0 \pm 3$ picomoles $/ 1 \mathrm{mg}$ protein/hr. All other actual values may be calculated from this.
Beharioral results. Following injection informal observations of animals over the $1 \mathrm{hr}$ preceding behavioral testing indicated virtually all $(=-80 \%$ ) experimental animals engaged in vigorous stereotyped sniffing and gnawing of the wood bedding of their cages. Few $(<1(0 /)$ control animals showed this behavior, and no other behavioral changes were obvious in the observation period. This change in hehavior has been observed previously [17]. In the present design drug treated animals continued to show high levels of sniffing during experimental observations. Gnawing and hiting and repetitive motor activity were not observed however it must be noted that the open field was a flat surface, and typically lacked objects with which these behaviors could be expressed.

Effects of these drugs upon motor activity (grid cros. sings), rearing. and defecation are presented in Figs. 1. 2 and 3. In Fig. 1, a dose related decrease in ambulation was found for both compounds. Effects of both drugs and session interval were significant, $F(4.85)$ drug $-14.1, p \cdot 0.001: F(3,255)$ session interval $-13.25,1,0.001$. while there was no significant interaction between these variables. F(12.255) 1.6. $p=0.1$. Moreover, equivalent amounts of PNMT inhibition produced similar behavioral effects. Figure 2 presents similar findings for rearing. Again, the drug effects were dowe related, and roughly correlated behaviorally for hiochemically equivalent effects. Both main effects were again signifi. cant. $F(4,85)$ drug-9.81,, 0.001 : $F(3.225)$ session interval-11.1,,$\cdot 0 .(0) 1$. Again, no interaction was present. $F(12.255)-1.0 . p=0.4$. Figure 3 presents defecation scores. Both drugs caused a dose-related decrease in defecation. Despite equivalent degrees of PNMT inhibition. ICMB had a more powerful effect on defecation. The apparent correlation of inhibition and dependent variable was therefore less clear in this last case. $F(4,85)$ drug $-5.92, p^{\cdot} 0.005$.

\section{DISCUSSION}

Relatively few studies have specifically addressed either the role of epinephrine or of inhibitors of PNMT upon behavior. Nonetheless. our results are consistent with results obtained from central injection of epinephrine in the mouse

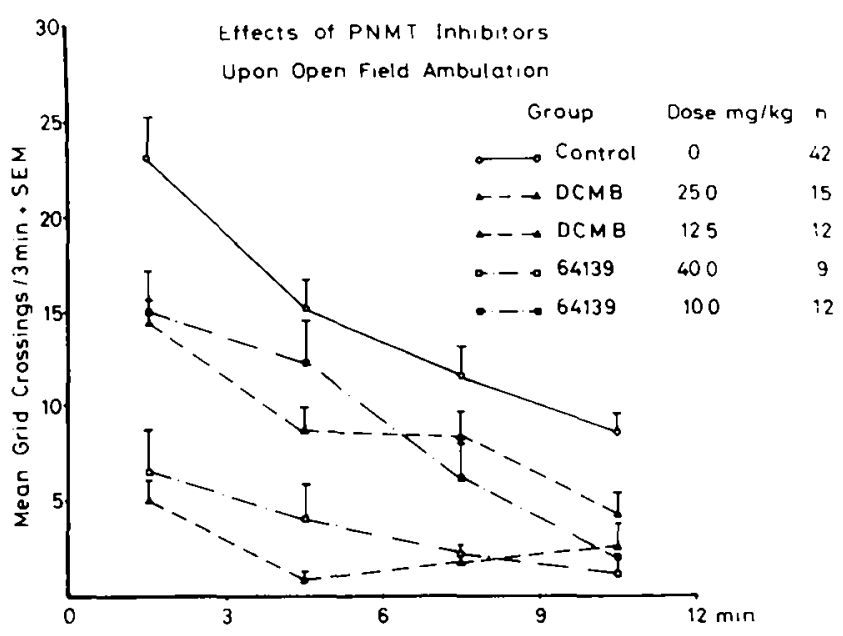

FiCi. 1. SKF 64139 and Lilly DCMB reductions in open tield hehavior (ambulation). All data as mean .t standard error. 


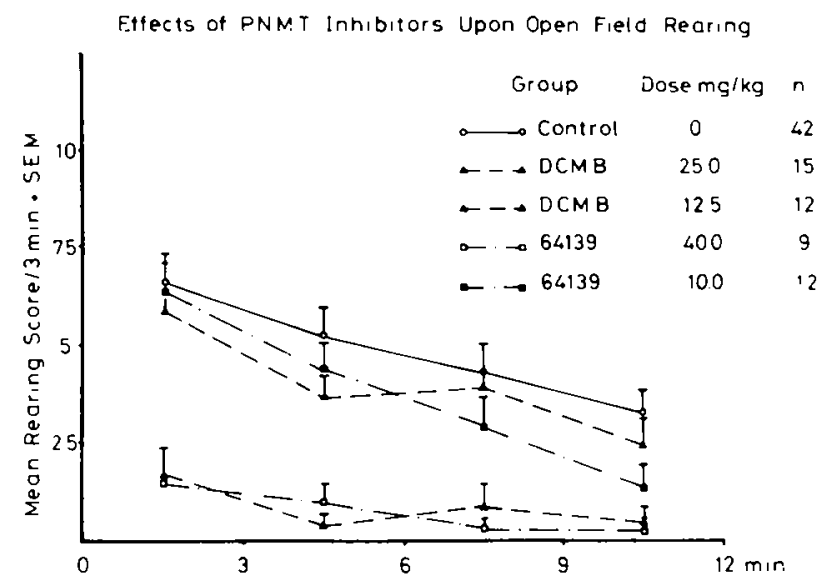

FIG. 2. SKF 64139 and Lilly DCMB reductions in open field behavior (rearing). All data as mean and standard error.

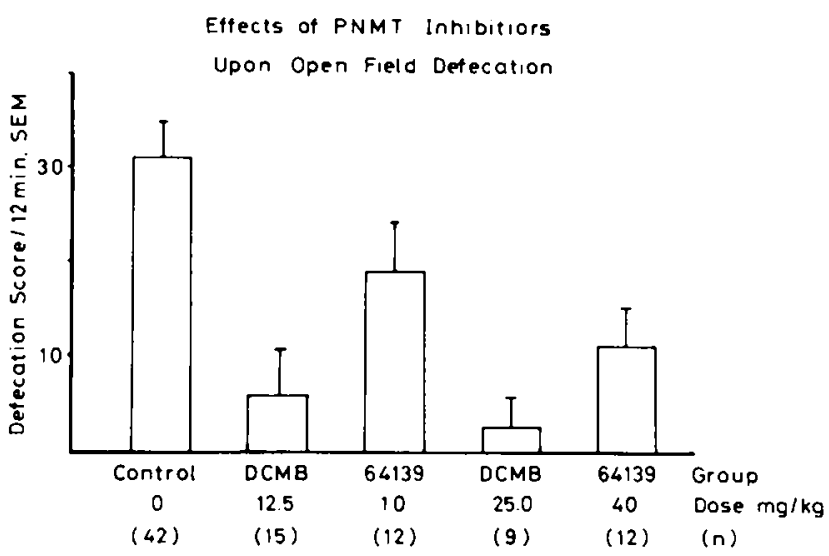

FIG. 3. SKF 64139 and Lilly DCMB reductions in open field behavior (defecation). All data as mean and standard error.

$[12,23]$ as well as with our own earlier observations [17] in rats. Adrenergic stimulation has previously been shown to increase motor activity and we have shown an acute lowering of activity after adrenergic inhibition. Observations upon behavioral depression after yohimbine, a blocker of adrenergic sensitive adenyl cyclase $[9,36]$ also support a role for epinephrine in the facilitation of motor behavior. A variety of different experiments using adrenergic stimulation and inhibition therefore suggest a facilitatory role for $E$ in motor behavior.

Our specific findings of decreased ambulation and rearing and possibly increased stereotypy suggest that adrenergic systems normally facilitate exploration but inhibit stereotypy. Clearly an assessment of drug effects upon activity must carefully account for the testing paradigm employed, and in the present circumstances we emphasize two separate sets of behavioral observations.

The similarity of behavioral changes after different drug treatments which produced similar changes in brain PNMT further supports this system as the mediator of the two observed behavioral syndromes. It would appear from our results that adrenergic systems do participate in the control of motor activity. This might also be expected in part from studies reporting moderate PNMT concentrations in areas associated with motor control, e.g., within the substantia nigra and basal ganglia |19]. Low but measurable amounts of enzyme have also been reported in other CNS areas associated with motor control, e.g., in the cerebellum and red nucleus of several primate species, including man [19].

We feel that two interpretations of the changes in open field behavior are possible. By the first. the action of $E$ is direct, e.g., as a necessary component of a final common path for behavioral expression. The second interpretation assigns a modulatory role to $E$, i.e., E containing neurons may affect another system which in turn controls motor activity. The present findings are consistent with either interpretation. However. we feel particular attention should be paid to the latter. On the one hand previous histochemical findings do not report Epi in motor neurons. Moreover, behavioral and anatomical evidence are consistent with an indirect mode of action. We have pointed out that $E$, in fact, innervates DA containing areas of the extrapyramidal motor system, as well as other motor areas. Our findings suggest an increase in stereotyped sniffing and gnawing after PNM'T inhibition. It is possible E governs DA systems by exerting a tonic inhibition upon them. While it is not clear that motor inhibition and stereotypy are always or necessarily inimical at a behavioral level, a number of experiments (e.g. , $[26,30]$ ) suggest cases of DA mediated stereotypy may be characterized by relative decreases in ambulation and rearing. Certainly, this is consistent with our findings.

It might also be noted that PNMT inhibition facilitates other stereotyped behaviors which are DA mediated at least in part [17]. Perhaps the most direct evidence for this may be found in recent preliminary observations from our laboratory. that adrenergic inhibition facilitated DA dependent DOPA induced behaviors. While continued investigations of the neural systems involved is necessary. our results do suggest a behavioral significance for adrenergic systems and a possible relation to DA.

\section{ACKNOWLEDGEMENTS}

The authors gratefully acknowledge postdoctoral support provided by the National Institute of Mental Health (Grant 07417 to Drs. Katz and Turner through the Mental Health Research Institute). We thank Dr. Roy Fuller of the Lilly Research I aboratory and Dr. Robert Pendleton of Smith. Kline and French Laboratory for their generous donations of Lilly DCMB and SKF 64139. respectively. as well as for their advice: and Cindy Reynolds and Ruth Koerber for their editorial assistance.

\section{REFERENCES}

1. Anden, M. F.. U. Strombom and T. H. Svensson. Dopamine and noradrenaline receptor stimulation: reserpine induced suppression of motor activity. Psychopharmacologia 29: 289-298. 1973.
2. Barchas. J. D., R. D. Ciaranello and A. M. Steinman. Epinephrine formation and metaholism in mammalian brain. Biol Psichicur. 1: 31-48. 1969. 
3. Benkert, O. and B. Kohler. Intrahypothalamic dopamine and norepinephrine injections in relation to motor hyperactivity in rats. Prschopharmacologia 24: 318-325. 1972.

4. Brittain, R. T. and S. L. Handley. Temperature changes produced by the injection of catecholamines and 5-hydroxytryptamine into the cerebral ventricles of the conscious mouse. J. Physiol., Lond. 192: 805-813. 1967.

5. Corden. J. P.. J. DeChamplain and B. Jacks. Excitation and prolonged waking produced by catecholamines injected into the ventricular system of cats. (an. I. Phisiol. Pharmac. 49: 627631,1971

6. Dixon. W. J. Biomedical computer Programs. Berkeley: Univ. Calif. Press. 1975.

7. Fuller. R.. B. W. Roush, H. D. Snoddy and B. B. Molloy. Inhibition of phenylethanolamine- $\mathrm{N}$-methyltransferase by benzylamines 2 : In vitro and in vivo studies with 2,3 dichloro- $\alpha$ methylbenzylamine. J. Med. (he'm. 16: 106-109, 1973.

8. Fuller, R. W. and K. W. Perry. Lowering of epinephrine concentration in rat brain by 2,3 Dichloro- $\alpha$-methylbenzylamine. an inhibitor of Norepinephrine-N-methylt ransferase. Bioche'm. Pharm. 26: 2087-2090. 1977

9. Goldstein, M.. J. Y. Lew, Y. Mutsumoto, T. Hokfelt and K. Fuxe. Localization and function of PNMT in the central nervous system. In: Psuchopharmacology, A cionerafion of Progress. edited by M. A. Lipton, A. Dimascio and K. F. Killam. New York: Raven Press, 1978, pp. 261-269.

10. Goldstein, M., J. Y. Lew, T. Miyamoto, A. F. Battista, R. Ebstein, T. Hokfelt and $K$. Fuxe. The localization and characterization of phenylethanolamine- $\mathrm{N}$-methyltransferase activity in specific regions of the central nervous system. Phatmacologist 16: 236, 1974

11. Grunden, 1.. R. Action of intracerebroventricular epinephrine on gross behavior. locomotor activity. and hexobarbital sleeping times in rats. Int. J. Neurophurm. 8: 573-586, 1969.

12. Haley, T. J. and W. G. McCormick. Pharmacological effects produced by intracerebral injection of drugs in conscious mice. Br. I. Pharmac. 12: 12-15. 1957.

13. Herman, Z. S. The effects of noradrenaline on rats behavior. Prychupharmacologia 16: 369-374. 1970.

14. Hokfelt, 'T., K. Fuxe, M. Goldstein and O. Johansson. Immunohistochemical evidence for the existence of adrenaline neurons in the rat brain. Brain Res. 66: 235-251, 1974.

15. Jackson, D. M.. N. E. Anden and A. Dahlstrom. A functional effect of dopamine in the nucleus accumbens and in some other dopamine-rich parts of the rat brain. Psuchopharmacologia 45: $139-149,1975$

16. Katz. R. J.. G. Baldrighi and B. J. Carroll. Fffects of nomifensine (HOE 984) upon psychomotor activity and intracranial self-stimulation in the rat. Pharmas. Biochem. Behas. 7: 269272. 1977.

17. Katz. R. J.. B. J. Carroll and I.. I eibler. Enhancement of drug induced motor activity by an inhibitor of phenylethanolamine-N-methyltransferase. Vemonci. l.e"l. 8: 83-88, 1978.

18. Khalsa, J. H., G. Gessner. J. Sawyer, H. Sarau and R. G. Pendieton. Inhibitory effects of SKF 64193 on phenylethanolamine- $\mathrm{N}$-methyltransferase (PNMT) in rat brain. Pharmacologist 18: 209, 1977.
19. Lew, J. Y., Y. Matsumoto, J. Pearson, M. Goldstein. T. Hokfelt and $K$. Fuxe. Localization and characterization of phenylethanolamine- $\mathrm{N}$-methyltransferase in the bratins of various mamnalian species. Brain Re's. 119: 199-210, 1977.

20. i.owry. O. H. N. J. Rosenburg, A. L. Farr and R. J. Randal. Protein measurement with the Folin phenol reagent. I. Biol. (hem. 193: 265-275, 1951.

21. Malec, D. and $Z$. Kleinrok. The spontaneous motility of rats after intraventricular injection of dopamine. Nouropharmac. 11: 331-336, 1972 .

22. Mandell. A. J. and C. E. Spooner. Psychochemical research studies in man. Srience 162: 1442-1453, 1968.

23. Pellegrini-Quarantotti, B.. A. Scotti de Carolis and V. C. I.ongo. Behavioral effects of intracerebrally administered catecholamines in mice and their modifications by some adrenergic blocking agents. Prichopharmacologial 45: 83-86. 1975.

24. Pendleton, R. G., J. Khalsa, G. Gessner and J. Sawyer. Studies on the characterization and inhihition of rat hrain phenylethanolamine-N-methyltransferase. Vuum Situmiceleberg's Arch. Pharmac. 299: 219-224, 1977.

25. Pendleton, R. G., C. Kaiser and G. Gessner. Studies on adrenal phenylethanolamine-N-methyltransferase (PNMT) with SKF 64139, a selective inhibitor. $J$. Phamac. cop. The't. 197: 6236.32, 1977

26. Randrup. A. and I. Munkvad. Pharmacological, anatomical and psychological investigations of stereotyped behaviors induced by amphetamines. In: Amphefamines and Related (empormds, edited by F. Costa and S. Garattini. New York: Raven Press. 1970. pp. 695-713.

27. Saavedra. J. M. M. Palkovits. M. Brownstein and J. Axelrod. Localization of phenylethanolamine- $\mathrm{N}$-methyltransferase in the rat brain nulei. Nuruec, Lomd. 248: 695-696. 1974

28. Schulty, J. W., B. C. Reif, J. A. Bacher. Jr., W. S. 1 awrence and M. I. Tainter. Further study of central stimulation from sympathomimetic amines. I. Pharmas. (ev). Ther. 71: 62-74. 1941.

29. Segal. D. S. and A. J. Mandell. Behavior of rats during intraventricular infusion of norepinephrine. Pror. matn Acad. S'i. U.S.A. 66: 289-293, 1970.

30. Segal. D. S. and A.J. Mandell. L .ong term administration of d-amphetamine: progressive augmentation of motor activity and stereotypy. Pharmac. Bischem. Behal. 2: 245-259. 1974.

31. Smith. (j. P. The arousal function of central catecholamine neurons Alum. N.Y. Acul Siri. 270: 45-56, 1976

32. Stromberg. L. Dopa effects on motility in mice-potentiation by MK 485 and dexchlorpheniramine. Purtophormonologia 18: $58-69.1970$

33. Turner. B. B.. R. J. Katz, K. A. Koth. B. J. Catroll. Central elevation of phenylethanolamine- $N$-methyltransferase activity following stress. Brain Re's. 1978. in press.

34. Ungerstedt, U. Brain dopamine neurons and hehavior. In: Norurosciences Third Studs Program. edited by F. O. Schmitt and $\mathrm{F}$. G. Worden. Cambridge: MII Press. 1975, pp. 695-703.

35. Ungerstedt, U.. I. L. Butcher. S. G. Butcher. V. F. Anden and K. Fuxe. Direct chemical stimulation of dopaminergic mechanisms in the neostriatum of the rat. Broin Re, 14: 461-471. 1969.

36. Zehrowska-Lupina. I. and $\%$. Kleinrok. Behavioral effects of yohimbine administered intraventricularly in the ritt. Pswchopharmacologia 33: 267-275, 1973 